\title{
Management of information within Portuguese families with Huntington disease: a transgenerational process for putting the puzzle together
}

\author{
Carla Roma Oliveira $\mathbb{1}^{1,2} \cdot$ Álvaro Mendes $\mathbb{1}^{3} \cdot$ Jorge Sequeiros $\mathbb{1}^{4} \cdot$ Liliana Sousa $^{5}$
}

Received: 24 October 2019 / Revised: 27 March 2020 / Accepted: 7 April 2020 / Published online: 27 April 2020

(c) The Author(s), under exclusive licence to European Society of Human Genetics 2020

\begin{abstract}
Huntington disease (HD) is a rare progressive neurological disease, with no cure, inherited in an autosomal dominant fashion, significantly impacting family relations, health and well-being. So far, no studies have reported how Portuguese families deal with information about HD, from a transgenerational perspective. This qualitative study aims to fill in that gap, and focuses on how families acquire knowledge about HD and management of information within the family and in their social relationships. The study adopted semi-structured interviews with 10 participants from HD families. Interviews were transcribed and analysed thematically. Findings suggested that management of information in the family started with the search for a diagnosis in an affected family member. Diagnosis led to a process of "making sense of HD in the family", which activated a transgenerational process to understand HD in the family context, marked by improved awareness and different ways family members manage it (closedness and openness). These results should be relevant for health-care professionals, bringing further insight into the process of acquiring knowledge about HD, and highlighting the relevance of continued efforts for enhanced pre- and post-test counselling and ongoing support to the HD families.
\end{abstract}

Carla Roma Oliveira

carlaromaoliveira@ua.pt

1 Department of Education and Psychology, CINTESIS (Centre for Health Technology and Services Research), University of Aveiro, Aveiro, Portugal

2 UnIGENe, IBMC - Institute for Molecular and Cell Biology, i3S Instituto de Investigação e Inovação em Saúde, University of Porto, Porto, Portugal

3 UnIGENe and CGPP - Centre for Predictive and Preventive Genetics, IBMC - Institute for Molecular and Cell Biology, i3S Instituto de Investigação e Inovação em Saúde, University of Porto, Porto, Portugal

4 UnIGENe and CGPP - Centre for Predictive and Preventive Genetics, IBMC - Institute for Molecular and Cell Biology, i3S Instituto de Investigação e Inovação em Saúde, Univ. Porto, Portugal; and ICBAS - Instituto de Ciências Biomédicas Abel Salazar, University of Porto, Porto, Portugal

5 Department of Education and Psychology, CINTESIS (Centre for Health Technology and Services Research), University of Aveiro, Aveiro, Portugal

\section{Introduction}

Huntington disease (HD) is a progressive neurological disease of late-onset, inherited as an autosomal dominant condition, combining severe motor, cognitive and behavioural symptoms, still with no effective treatment [1]. Its age at onset, however, varies widely, with some known juvenile and infantile cases [2]. HD usually shows high penetrance, but incomplete correlation of age-at-onset with size of the expanded repeat, together with early deaths in previous generations from other causes, or occurrence of reduced penetrance alleles, add further uncertainty about its expression [3]. Initial symptoms may be easily mistaken with other conditions (such as depression, schizophrenia, Parkinson or Alzheimer disease), particularly in families without known family history $[4,5]$. The prevalence of HD in Portugal has been estimated to be 5-10:100.000 [6-8]. This low prevalence, similar to that of other European countries [8], contributes to a limited awareness about the disease [9].

Predictive testing for Huntington disease, by linkage analysis, became possible shortly after its locus was mapped in 1984 [10]. It was only after the disease-causing (CAG)n expansion was found in 1993 [11], that direct genetic testing, including pre-symptomatic testing (PST) became 
available, allowing relatives at a $50 \%$ risk the possibility to know if they are carriers. As an effective and acceptable medical intervention is still lacking, PST provides individuals with information without any direct clinical benefit. This raised concerns particularly regarding its psychological, familial and social impact. In Portugal, a national PST programme was first established in 1996 for MachadoJoseph disease, and extended to other late-onset neurological diseases, including HD, in 1998, offering genetic counselling and psychological support and follow-up $[12,13]$. PST for HD is available at the five medical genetic services integrating the National Health System, as well as in a few private centres [14].

There are some studies in Portugal addressing individuals' experiences, motivations and illness representations (e.g., illness beliefs and expectations) related to PST, including for HD, as well as its psychological impact [15]. None of these studies, however, addressed the specific experience of how families with HD manage the information related to this condition. Indeed, counselling experience and research evidence showed that genetic information is a family matter with interpersonal and intergenerational impact [16, 17]. Family members often have limited knowledge or are oblivious about HD and, often, only find out about its existence in the family when a relative, or themselves, are diagnosed [18, 19]. Informing family members about HD may be emotionally demanding and cause or amplify existing difficulties in relationships, affecting the dynamics of disclosure of information about HD in the family, including to younger generations [19-21]. This can be further complicated by identity adjustments in individuals after PST [22], mostly due to the need to realign one's outlook, lifestyle choices and relational expectations. Fear of stigma and discrimination has been reported, leading to secrecy and shame [23-26]. In familial amyloid polyneuropathy (FAP) families, older members play a role in disseminating information about family history, that promotes awareness about the familial disease in younger members; older relatives had a supportive role when younger ones had an unfavourable PST result [27].

This study aims to explore how families with HD in Portugal manage information about the disease, from a transgenerational perspective. It focuses on the process of acquiring knowledge about the disease, positioning of its members in relation to that knowledge, and management of information within the family and in their social relationships.

\section{Methods}

This exploratory qualitative study was drawn from a larger study that examines intra and inter-generational transmission of health behaviours among families with late-onset hereditary diseases [27], including HD. Ten interviews covering this theme were conducted with members of families with HD. We present here the sub-corpus of data, related to the participant's experiences of managing information about HD within the family.

\section{Procedure}

The study was presented in detail to representatives of the national patients' association, which mediated the recruitment of participants, disclosing it to their associates. Eligible participants included members of families with HD, aged 18 years or more and capable of giving informed consent. Potential participants showing interest in the study contacted the main researcher (first author), by telephone or email, who explained the study in detail. After agreement, interviews were scheduled and informed consent obtained. This was complemented by snowball sampling [28]. Ethical approval was sought and granted (UICISA: E-Ref. P595-05/ 2019).

\section{Instrument}

The main researcher conducted semi-structured interviews with 10 participants, via telephone (8), skype (1) or face to face (1). Average duration was $41.5 \mathrm{~min}$, ranging 20 to 67 min. An interview-guide was developed, consisting of a main question about transgenerational transmission of health behaviours, asking participants to report events they experienced in their family that were significant and meaningful to their disease experience. The interviewer was flexible in exploring other issues that emerged as significant during participants' accounts, and asked about their personal and transgenerational familial experience: when and how they knew about the diagnosis of HD; if and how that information was shared with relatives or friends; and its impact on interviewees and in their family and social networks. Social and demographic data (age, gender, education) were collected, as well as disease-status (affected, asymptomatic carrier, non-carrier, non-biological relative) from participants and the family members they mentioned during the interviews.

\section{Participants}

The study comprised 10 participants, from 7 families. Demographic and social data, disease status and family relationship of participants are described in Table 1.

\section{Analysis}

Interviews were audiotaped, transcribed and submitted to qualitative thematic analysis, using grounded-theory 
Table 1 Demographic and social data and disease status of participants.

\begin{tabular}{|c|c|c|c|c|c|}
\hline Family & $\begin{array}{l}\text { Participant (interviewee) } \\
\text { and kinship }\end{array}$ & Details of the families' relational context & Age & Gender & Schooling \\
\hline F1 & $\mathrm{P} 1$ & $\begin{array}{l}\text { P1 is spouse of an affected-carrier ( } 1^{\text {st }} \text { family diagnosis } 10 \text { years ago); } \\
\text { presumes HD was inherited from spouses' undiagnosed mother. No } \\
\text { children. }\end{array}$ & 67 & M & 12 years \\
\hline $\mathrm{F} 2$ & $\begin{array}{l}\text { P2 (daughter of P4) } \\
\text { P4 (mother of P2) }\end{array}$ & $\begin{array}{l}\text { P2 (non-carrier) is P4's daughter; P4 is spouse of an affected-carrier } \\
\text { (diagnosed } 5 \text { years ago); HD was inherited from P4's mother-in-law } \\
\text { (unknown diagnosis date); P4 has two other children who have not } \\
\text { undertaken PST (one } \leq 18 \text { ). }\end{array}$ & $\begin{array}{l}29 \\
60\end{array}$ & $\begin{array}{l}\mathrm{F} \\
\mathrm{F}\end{array}$ & $\begin{array}{l}\text { University degree } \\
\text { University degree }\end{array}$ \\
\hline F3 & $\begin{array}{l}\text { P3 (sister-in law with P6) } \\
\text { P6 (sister-in-law with P3) }\end{array}$ & $\begin{array}{l}\text { P3 and P6 are sisters-in-law; P3 is the spouse of a non-carrier and } \\
\text { daughter-in-law of an affected carrier (father-in-law; } 1^{\text {st }} \text { family diagnosis } \\
10 \text { years ago); P6 is the spouse of an affected-carrier (diagnosed } 8 \text { years } \\
\text { ago). HD presumed to have been inherited from P6 spouses' undiagnosed } \\
\text { grandfather. P6 has one child (who has not undertaken PST). }\end{array}$ & $\begin{array}{l}44 \\
43\end{array}$ & $\begin{array}{l}\mathrm{F} \\
\mathrm{F}\end{array}$ & $\begin{array}{l}12 \text { years } \\
8 \text { years }\end{array}$ \\
\hline F4 & P5 & $\begin{array}{l}\text { P5 is a non-carrier, daughter of an affected carrier (mother; } 1^{\text {st }} \text { family } \\
\text { diagnosis } 5 \text { years ago); HD is presumed to have been inherited from her } \\
\text { symptomatic but undiagnosed maternal grandfather. P5 has two other } \\
\text { sisters (one non-carrier; the other has not undertaken PST). }\end{array}$ & 28 & $\mathrm{~F}$ & University degree \\
\hline F5 & $\begin{array}{l}\text { P7 (niece of P9) } \\
\text { P9 (uncle of P7) }\end{array}$ & $\begin{array}{l}\text { P7 is an asymptomatic carrier (PST } 11 \text { years ago). P7 is P9's (non- } \\
\text { biological) niece. P7's mother is an affected carrier (diagnosed } 14 \text { years } \\
\text { ago), who inherited HD from her diagnosed father ( } 1^{\text {st }} \text { family diagnosis, } \\
\text { for over } 20 \text { years). } \\
\text { P9's spouse (P7's biological aunt) has never undertaken PST and is } \\
\text { asymptomatic. P9 has no children. }\end{array}$ & $\begin{array}{l}33 \\
72\end{array}$ & $\begin{array}{l}\mathrm{F} \\
\mathrm{M}\end{array}$ & $\begin{array}{l}\text { University degree } \\
7 \text { years }\end{array}$ \\
\hline F6 & P8 & $\begin{array}{l}\text { P8 is an asymptomatic carrier (PST } 6 \text { years ago). P8's father was an } \\
\text { affected carrier ( } 1^{\text {st }} \text { family diagnosis } 6 \text { years ago); HD is presumed to have } \\
\text { been inherited from P8's symptomatic though undiagnosed paternal } \\
\text { grandmother. P8 has another sister (who has not undertaken PST). }\end{array}$ & 37 & $\mathrm{~F}$ & University degree \\
\hline F7 & $\mathrm{P} 10$ & $\begin{array}{l}\text { P10 is the ex-spouse of an affected carrier ( } 1^{\text {st }} \text { family diagnosis } 14 \text { years } \\
\text { ago); she has a carrier son (diagnosed } 6 \text { years ago) and a daughter who } \\
\text { still doesn't know her disease status }(\leq 18) \text {; HD inherited from the ex- } \\
\text { spouse's (asymptomatic) carrier father (diagnosis made after his son's). }\end{array}$ & 46 & $\mathrm{~F}$ & 12 years \\
\hline
\end{tabular}

methods of constant comparison and coding [29, 30]. The process consisted of identifying the themes that emerged more often and that better captured the participants' perception of the process of acquiring and managing information about HD in the family. Themes were then organised in order to portray narratives of the participants. This was an interactive process of refinement, involving two independent coders (first and last authors).

\section{Results}

Three main themes were identified: 1) "searching for a diagnosis" in an affected relative, that prompted the management of information about HD in the family; 2) "making sense of HD in the family", which occurred after diagnosis in a proband and activated the transgenerational process of understanding HD in the family context (how the pieces of the puzzle fit together); and 3) "managing HD in the family", which was marked by the new awareness and how family members positioned themselves in relation to the disease in the family, punctuated by two coexisting modes closedness and openness.

Extracts of interviews are included next to enable further understanding of the themes. Extracts are identified by a code (Table 1), to assure confidentiality. Content in square brackets is used to add intelligibility to the participants' quotations or to suppress information that might compromise confidentiality; "(...)" indicates content that was omitted for the sake of space or clarity.

\section{Searching for a diagnosis}

Getting a diagnosis of HD is a long and hard process: P3: it was a long battle until we finally knew what was going on. It usually starts when mild symptoms are noticed in a close relative: P1: something that was not normal (...) but she kept on with her regular life; or P4: I thought he was irritated, as his reactions were very exaggerated. As symptoms became more evident, mostly at the behavioural and 
cognitive level, families looked for help from specialised professionals, commonly a psychiatrist or neurologist. In this process, they reported having received erroneous diagnoses from Parkinson or Alzheimer disease and schizophrenia, to brain tumour or childhood trauma. Some patients went through long psychiatric and/or neurological follow-up, frequently without an established HD diagnosis: P1: although back then she [wife] was attending psychiatrists, no one ordered a test or has mentioned HD. So, we were surprised when other symptoms started. Four participants indicated periods from 5 to 15 years between relatives first medical appointments and a HD diagnosis. One participant referred to her symptomatic grandfather who died without a HD diagnosis, after living with symptoms for at least 8 years. Others only made reference to long periods without specifying how long. Shorter periods of time were stated concerning relatives with close relations to medical professions.

This "diagnostic odyssey" was disturbing to families, especially as symptoms continued to progress without them reaching a clear and convincing explanation: P6: No! This can't go on like this, there's something wrong, he [father in law] worsens each day (...) this clearly isn't just a child trauma. Thereafter, relatives started searching for information online or with friends with contacts in the health system. One participant reported that the information about HD came from watching a TV programme where HD had been mentioned, which shed light to his concerns: P1: I then started to realize that the pieces of the puzzle fitted together. When they had a first clue that their relative's disease could be HD, another journey begun to find the right medical advice (hospital, physician); sometimes they searched online and found about the patients' association; others activated connections in the health system that helped them arrange an appointment and referral for genetic testing.

The diagnosis came with challenging information: a rare hereditary disease, without effective treatment or prevention, with a 50\% chance of passing/having passed the altered gene to offspring: P8: The doctor told me: your father has HD, this is hereditary, you have a 50\% chance of getting the disease and there is no treatment or cure. Diagnosis is often described as shocking: P5: it was a big shock; P8: I found out that I could have the disease at 20 and I was clueless about it. However, it also allowed the participants (and their families) to "put the pieces of the puzzle together" and understand the course of HD in the family.

\section{Making sense of HD in the family}

After the diagnosis, family members search for information about the disease and look back to previous generations to try to understand who was affected: P5: Back then, we didn't know, there was still no knowledge [about HD] in the family. Today, we know that my grandfather also had it, because now we know the disease and are able to identify the symptoms. From here, participants reported that other family members underwent testing, while others decided not to. Looking at previous generations brought participants increased knowledge about:

(i) From whom the disease came, who had it, and who might have it in current generations: P1: (...) when she was told it was hereditary, [participant's wife name] realized that the problem came from her mother; $\mathrm{P} 4:$ We have an older daughter (...), I think she is ill because she also has some alterations. The process of understanding HD in previous generations often makes family members aware of their limited knowledge about the family's past (in general, not just HD-related).

(ii) What symptoms previous generations were facing, and what challenges are associated: Some participants recognised past generations were unaware about HD: P4: They lived with someone who was very ill [participant's mother in law], who died, who was very close, but no one knew what it was [HD]. The stories they heard involved family members with "bad temper", "madness", "nervous disease", together with motor incoordination, witchcraft (involuntary movements being associated to possession) or alcoholism: P8: Back then, my grandmother was said to be a witch, because of the involuntary movements; P9: My father-in-law used to come home with those choreic movements and people started saying he had been drinking. Participants reported situations of shame and stigma: P8: They don't tell much, because my father's family was very afraid of what others could think or say (...); this [HD] was a taboo, one would not speak nor admit it because they'd be ashamed.

(iii) A new understanding of (dysfunctional) interactions with and between affected relatives: P8: My father was very violent (...) he'd beat everybody up and I couldn't understand why he beat me. (...) Then the doctor explained it could be due to HD.

\section{Managing HD in the family}

Participants acknowledged that if they had known about HD previously to the diagnosis of their relatives, they would have managed the situation differently (e.g., not arguing/ confronting them when exhibiting what they now know were HD symptoms, or giving them additional/different help): P5: If we had known about the disease we would have helped differently, (...) we could have done something, he 
[grandfather] didn't have a life because we didn't know [it was HD]. Managing HD, however, demands additional challenges as most family members lack knowledge about basic genetics and heredity: P5: My grandmother hardly understands that he [grandfather] had that disease and that my mother has that disease, that it is about genetics.

Participants also reported the coexistence of two main ways of managing HD information, in different family members: closedness and openness. Closedness is an attitude through which people deny the disease or prefer not to know their genetic status (or their relatives'), thus not uptaking PST, or not supporting their relatives to do it: P8: My father never assumed he was ill or he had an illness; P5: My older sister never did the test. (...) She doesn't deal well with the disease, she drinks, she's not working. She believes she has the disease and that she will die and so she has to enjoy life now.

Closedness manifests also by avoidance of talking about HD, even with close relatives. This is described as a selfprotection mechanism (fear of rejection) and a means to protect others from alarm and upsetting information: P6: $M y$ son does not speak, (...) I do not know if it is fear that he may also have it, but he keeps it to himself; P2: (...) I thought everyone would stop being friends and that they would abandon me, because I would have psychotic behaviours, which would affect the others, and they would not want to deal with it.

In other cases, withdrawal from social networks (but not from close relatives) occurred and involved isolation or moving to another town. Participants described how affected people refrain from going out, because they feel ashamed of showing symptoms: P5: One of the things that helped was leaving the city where she [mother] was living. It was difficult for her that people who knew her before would see what she was becoming.

Openness is a posture adopted by some family members that involves accepting the disease, without (overtly) expressing shame or embarrassment: P10: [describing her reaction when she was interviewed for a TV show over HDrelated shame] Shame? What shame? I am not ashamed! I have a sick son, I'm not ashamed. Some participants described they were keen to maintain their activities of daily life (e.g. continuing to go to the hairdresser, shopping, etc.), without reclusion of the affected relative away from the family's social environment. This involved a proactive attitude of keeping their relative integrated, while being supportive and caring: P1: (...) I always tried that [wife's name] was as integrated as possible. (...) I have never hidden her disease from anyone (...), we would go out for a walk or to the hairdresser (...) or even to the same restaurant.

This posture also involved searching for information with a focus on becoming active within the disease community (e.g. attending to conferences or becoming a member of the patients' association). It also involved being open about sharing this information with other family members (e.g. about latest developments or clinical trials) and with the community: P10: We must face this situation [disease] normally (...). Society must get used to see people that are different and accept them as they are".

This open and normalising posture was reported as being helpful for the younger relatives to face the disease more openly: P2: (...) my mother helps my father in everything (...), but she also helps other people that might have the disease (...). My mother made me realize that it is possible for someone to love us, to stand by us, not abandoning us because we have a disease.

\section{Discussion}

This study shows that management of information about HD is a transgenerational process, where past and present experiences are brought together to make sense of the puzzle of the family disease history. This is the first study to report experiences of Portuguese families with HD in dealing with this information and how they have gone through the process of integrating that information in their lives.

Most participants describe getting a diagnosis as a turning point. This process is portrayed as an odyssey [31], involving a long, strenuous course, marked by acute suffering, uncertainty and sudden contact with frightful information, which suggests that neither their social environment nor healthcare providers are sufficiently aware of HD. This diagnostic odyssey was not reported in Portugal for other rare adult-onset neurological diseases (namely FAP, and Machado-Joseph disease-MJD/SCA3), probably because, unlike HD in Portugal, patients distribute mainly in national geographic clusters for those diseases [32, 33], leading to increased awareness. Similarly to other studies, in populations with low prevalence and in families with unknown family history, such delay in obtaining a diagnosis of HD (or even cases of misdiagnosis) is common [4, 18].

Knowing a diagnosis of HD is a complex event that challenges families and their members to reposition themselves regarding this new information. They can finally give a name to what they had been experiencing; but, at the same time, they find themselves dealing with a hereditary, severe, fatal disease, without effective treatment. Individuals first tend to understand who had the disease in the past and from "whom" it came. This triggers a process of understanding it from a transgenerational perspective [34], where family members collect "missing pieces" to "make sense of the puzzle of the familial disease". However, this becomes more than an exercise of "mutual surveillance", where 
members continually scrutinize other relatives for signs of HD [35], as they realise they know very little about previous generations and their family history. Probably reflecting secrecy-based strategies, families tend to conceal HD symptoms, which are often associated to stigmatising blameworthy behaviours (e.g., alcoholism, witchcraft, madness, nervous disease) [26, 36-38]. In our opinion these are often amplified with guilt, shame and fear of discrimination in cultures with a strongly rooted JudaeoChristian tradition, including strong catholic values, conservativeness, little openness to the exterior, poverty together with scant investment in public healthcare, all of which were more intense during the fascist dictatorship in Portugal (up to 1974).

Some participants reported that diagnosis and knowledge of HD in the family allowed them to understand better some relational features in their families, namely strained relationships with close relatives. Furthermore, awareness about HD challenges families to adjust their communication and coping strategies, which entails a change in family identity: from a family of mad, bizarre people, to a family facing a severe rare genetic condition, less attached to shame and stigma. Confronting it, however, is challenging and potentially burdensome [19, 22, 39].

Participants reported two main coping strategies that may coexist within the family: closedness and openness. Closedness seems attached to a relational transmission from previous generations (that did not know about HD) and adopted it to face shame and stigmatisation. In current generations it is associated to denial of the disease, nonengagement with PST, avoidance of talking about HD, or social withdrawal. Similar circumstances have been described in Portuguese families with FAP [40]. Closedness may encircle a metaphorical way of silencing the disease, as well as the associated burden or prejudices [16, 38, 41]. From a transgenerational perspective, closedness could also represent the denial of this heritage [41], which can explain why references to PST occur so occasionally in most accounts. Moreover, limited references to PST may translate the participants' perception of the limited benefits of predictive knowledge (e.g., absence of treatment or cure). Yet, in a few instances, we can only hypothesize that it may be also a symptom of the disease and of its cognitive impairment.

Our findings suggest that openness may be a relatively recent mode within families and involves accepting and normalising the condition mainly towards younger generations. It particularly describes non-biological family members' (more often than carrier or non-carrier relatives') refusal to conform to shame, becoming in some cases vocal about HD in their communities. Families with HD and FAP showed similar responses to stigma and discrimination, described as resistance to being treated differently [38].
From a transgenerational perspective, this can be seen as creating new legacies, contributing to change their individual and family identity [42]. Openness seems to be an attempt to normalise the disease, moving on with their lives and influencing as much family members as they can, thereby affecting relationships both within and outside the family, and acting as a role model to younger members. This may be related to a sense of loyalty and "responsibility to protect" current and future generations $[19,43]$.

These results show a transgenerational process of managing the information about HD in Portuguese families. Participants' experiences suggest that getting a diagnosis of HD is still a difficult journey, which highlights the need for education of (genetic and non-genetic) health professionals, the media and the society at large. This work suggests shame and stigma are attached to the experience of $\mathrm{HD}$, although it also highlights acceptance and the development of support, in line with practices politically and socially more open around health and disease in the late $20^{\text {th }}$ to early $21^{\text {st }}$ century [44]. We think these results are relevant for healthcare professionals, namely in genetic counselling, as it contributes with an expanded perspective into the family dynamics in relation to the management of information about HD. Overall, this study highlights the importance of continued efforts for improved pre- and post-test counselling and support to HD families, in line with the international guidelines [45].

\section{Limitations and research perspectives}

The main limitation of this study was the reduced size of the sample. In addition, participants were mainly women, from the intermediate generation and non-biological or noncarrier family members, as pre-symptomatic carriers and affected individuals seemed more difficult to reach. A larger, more diverse sample would have allowed a better understanding of the management strategies within the family and a more sound exploration of the positioning of its members in relation to HD. The participants in this study had relatively high mean academic levels, for the Portuguese context, suggesting that people with lower education levels (usually associated to a lower socioeconomic status) might have more difficulties accessing a formal HD diagnosis, joining the national patient's association and adhering to a study like this. Upcoming research should also consider a wider range of education levels and explore intergenerational patterns of transmission of health behaviours and risk management, as well as family members' attitudes in relation to PST and information-sharing practices. In addition, and attending to the specific nature of $\mathrm{HD}$, future studies should include the familial management of care for patients, as well as a description and analysis of HD family networks. 
Acknowledgements The authors are indebted to all the participants in this study, for sharing their time and experience. The authors would also like to thank to the Portuguese Association of Huntington Disease for helping in the recruitment of the participants.

Funding Carla Roma Oliveira is the recipient of a Doctoral Fellowship from FCT (the Portuguese Foundation for Science and Technology) (SFRH/BD/131925/2017). Álvaro Mendes' work has the support of FCT (CEECIND/02615/2017). This article is also supported by FEDER through the operations POCI-01-0145-FEDER-007746 and POCI-01-0145-FEDER-007274, funded by the Programa Operacional Competitividade e Internacionalização - COMPETE2020 and by National Funds through FCT - Fundação para a Ciência e a Tecnologia, respectively within CINTESIS R\&D Unit (reference UID/IC/ 4255/2013) and Instituto de Investigação e Inovação em Saúde.

\section{Compliance with ethical standards}

Conflict of interest The authors declare that they have no conflict of interest.

Publisher's note Springer Nature remains neutral with regard to jurisdictional claims in published maps and institutional affiliations.

\section{References}

1. Bates GP, Dorsey R, Gusella JF, Hayden MR, Kay C, Leavitt BR, et al. Huntington disease. Nat Rev Dis Prim. 2015;1:1-21.

2. Hayden MR. Huntington's Chorea. London: Springer-Verlag; 1981.

3. Sequeiros J, Ramos E, Cerqueira J, Costa M, Sousa A, PintoBasto $\mathrm{J}$, et al. Large normal and reduced penetrance alleles in Huntington disease: instability in families and frequency at the laboratory, at the clinic and in the population. Clin Genet. 2010;78:381-7.

4. Halpin M. Diagnosis, psychiatry and neurology: the case of Huntington disease. Soc Sci Med. 2011;73:858-65.

5. Hoppitt T, Calvert M, Pall H, Rickards H, Sackley C. Huntington's disease [letter]. Lancet. 2010;376:1463-4.

6. Costa MC, Magalhães $P$, Ferreirinha F, Guimarães L, Januário C, Gaspar I, et al. Molecular diagnosis of Huntington disease in Portugal: implications for genetic counselling and clinical practice. Eur J Hum Genet. 2003;11:872-978.

7. Costa MC, Magalhães $\mathrm{P}$, Guimarães L, Maciel $\mathrm{P}$, Sequeiros J, Sousa A. The CAG repeat at the Huntington disease gene in the Portuguese population: insights into its dynamics and to the origin of the mutation. J Hum Genet. 2006;51:189-95.

8. Baig SS, Strong M, Rosser E, Taverner NV, Glew R, Miedzybrodzka Z, et al. 22 Years of predictive testing for Huntington's disease: the experience of the UK Huntington's Prediction Consortium. Eur J Hum Genet. 2016;24:1396-402.

9. Mustafa FA. Misdiagnosis of Huntington's disease [letter]. Lancet Psychiatry. 2017;4:21.

10. Gusella J, Gibbons K, Hobbs W, Heft R, Anderson M, Rashtchian $\mathrm{R}$, et al. The G8 locus linked to Huntington's disease. Am J Hum Genet. 1984;36:139S.

11. The Huntington's Disease Collaborative Research Group. THsDCR. A novel gene containing a trinucleotide repeat that is expanded and unstable on Huntington's disease chromosomes. Cell. 1993;72:971-83.

12. Paneque M, Félix J, Mendes Á, Lemos C, Lêdo S, Silva J, et al. Twenty years of a pre-symptomatic testing protocol for late-onset neurological diseases in Portugal. Acta Med Portuguesa. 2019;32:295-304.

13. Sequeiros J. O teste preditivo da doença de Machado-Joseph. Porto: Instituto De Biologia Molecular e Celular, Universidade do Porto; 1996.

14. Paneque M, Mendes Á, Saraiva J, Sequeiros J. Genetic counseling in Portugal: education, practice and a developing profession. $\mathbf{J}$ Genet Couns. 2015;24:548-52.

15. Lêdo S, Ramires A, Leite Â, Dinis MAP, Sequeiros J. Long-term predictors for psychological outcome of pre-symptomatic testing for late-onset neurological diseases. Eur J Med Genet. 2018;61:575-80.

16. McDaniel SH. The psychotherapy of genetics. Fam Process. 2005;44:25-44.

17. Rolland JS, Williams JK. Toward a biopsychosocial model for 21st-century genetics. Fam Process. 2005;44:3-24.

18. Etchegary H. Discovering the family history of Huntington disease (HD). J Genet Couns. 2006;15:105-17.

19. Sobel SK, Cowan DB. Impact of genetic testing for Huntington disease on the family system. Am J Med Genet. 2000;90:49-59.

20. Forrest K, Simpson SA, Wilson BJ, Van Teijlingen ER, McKee L, Haites N, et al. To tell or not to tell: barriers and facilitators in family communication about genetic risk. Clin Genet. 2003;64:317-26.

21. Featherstone K, Atkinson P, Bharadwaj A, Clarke A. Risky relations: family, kinship and the new genetics. 2006.

22. Brouwer-DudokdeWit AC, Savenije A, Zoeteweij MW, MaatKievit A, Tibben A. A hereditary disorder in the family and the family life cycle: Huntington disease as a paradigm. Fam Process. 2002;41:677-92.

23. Bombard Y, Penziner E, Suchowersky O, Guttman M, Paulsen JS, Bottorff JL, et al. Engagement with genetic discrimination: concerns and experiences in the context of Huntington disease. Eur J Hum Genet. 2008;16:279-89.

24. Etchegary H. Stigma and genetic risk: perceptions of stigma among those at risk for Huntington disease (HD). Qual Res Psychol. 2007;4:65-84.

25. Tibben A. Genetic discrimination in Huntington's disease. BMJ. 2009;338:b1281.

26. Wexler A. Stigma, history, and Huntington's disease. Lancet. 2010;376:18-9.

27. Oliveira CR, Mendes Á, Sousa L. From older to younger: intergenerational promotion of health behaviours in Portuguese families affected by familial amyloid polyneuropathy. Eur J Hum Genet. 2017;25:687-93.

28. Silverman D. Doing qualitative research: a practical handbook. SAGE publications limited; 2000.

29. Glasser B, Strauss A. The development of grounded theory. Chicago, IL: Alden; 1967.

30. Strauss A, Corbin J. Basics of qualitative research. Sage publications; 1990.

31. Black N, Martineau F, Manacorda T. Diagnostic odyssey for rare diseases: exploration of potential indicators. London: Policy Inovation Research Unit (PIRU), LSHTM; 2015.

32. Coutinho P, Ruano L, Loureiro JL, Cruz VT, Barros J, Tuna A, et al. Hereditary ataxia and spastic paraplegia in Portugal: a Population-Based Prevalence Study. JAMA Neurol. 2013;70:746-55.

33. Inês M, Coelho T, Conceição I, Duarte-Ramos F, de Carvalho M, Costa J. Epidemiology of transthyretin familial amyloid polyneuropathy in Portugal: a nationwide study. Neuroepidemiology 2018;51:177-82.

34. Bowen M. Family therapy in clinical practice. New York: Aronson; 1978.

35. Atkinson P, Featherstone K, Gregory M. Kinscapes, timescapes and genescapes: families living with genetic risk. Sociol Health Illn. 2013;35:1227-41. 
36. Cox SM. It's not a secret but- : predictive testing and patterns of communication about genetic information in families at risk for Huntington Disease [Doctoral Dissertation]. Vancouver: University of British Columbia; 1999.

37. Loi S, Chiu E. Witchcraft and Huntington's disease: a salutary history of societal and medical stigmatisation. Australas Psychiatry. 2012;20:438-41.

38. Coopman A-L, Janssen C. La maladie génétique au coeur de la fratrie: «tabou » et « secret ». Cah de psychologie Clin. 2006;27: $39-54$.

39. Arran N, Craufurd D, Simpson J. Illness perceptions, coping styles and psychological distress in adults with Huntington's disease. Psychol Health Med. 2014;19:169-79.

40. Mendes Á, Sousa L, Sequeiros J, Clarke A. Discredited legacy: stigma and familial amyloid polyneuropathy in Northwestern Portugal. Soc Sci Med. 2017;182:73-80.
41. Tisseron S. Le secret ne s'oppose pas à la vérité, mais à la communication. Cah Crit Thér Fam Prat Réseaux. 2004;33:55-68.

42. Thompson B, Koenig Kellas J, Soliz J, Thompson J, Epp A, Schrodt P. Family legacies: constructing individual and family identity through intergenerational storytelling. Narrative Inq. 2009;19:106-34

43. Hays A, Colaner C. Discursively constructing a family identity after an autism diagnosis: trials, tribulations, and triumphs. J Fam Commun. 2016;16:143-59.

44. Jogerst K, Callender B, Adams V, Evert J, Fields E, Hall T, et al. Identifying interprofessional global health competencies for $21^{\text {st }}$ century health professionals. Ann Glob Health. 2015; 81:239-47.

45. MacLeod R, Tibben A, Frontali M, Evers-Kiebooms G, Jones A, Martinez-Descales A, et al. Recommendations for the predictive genetic test in Huntington's disease. Clin Genet. 2013;83:221-31. 